\title{
Václav Havel: Erinnerungen an seine Präsidentschaft
}

\author{
Havel, Václav: Fassen Sie sich bitte kurz. Gedanken und Erinnerungen, deutsch von Joachim \\ Bruss, Rowohlt Verlag, Reinbek 2007, 416 Seiten, $€ 19,90$.
}

Václav Havel gehörte vor 30 Jahren in der Tschechoslowakei zu den Initiatoren der Charta 77, die unter Berufung auf die KSZE-Schlussakte von Helsinki Menschenrechtsverletzungen anprangerte und bürgerliche Freiheiten forderte. In der Folgezeit wurde er als einer der führenden Köpfe der antikommunistischen Opposition mehrmals verhaftet. Insgesamt verbrachte Havel fünf Jahre im Gefängnis. 1989 gründete er das Bürgerforum mit und leitete so das Ende des kommunistischen Regimes ein. Fortan galt er als „Held der Samtenen Revolution“. Havel avancierte vom Oppositionellen einer kommunistischen Diktatur zum Staatsoberhaupt einer demokratischen Republik. Von 1989 bis 1992 war er Präsident der Tschechoslowakei und nach der Teilung des Landes von 1993 bis 2003 Staatsoberhaupt Tschechiens - gewiss kein typischer Lebenslauf.

„Auch mir kommt von Zeit zu Zeit mein Schicksal absolut unwahrscheinlich vor. Wie konnte es nur geschehen, dass ich - und gerade ich - mich im Zentrum so wichtiger Ereignisse befand, die das Schicksal vieler Völker und Millionen von Menschen geprägt haben? Warum musste ich, ein Autor absurder Theaterstücke, Hunderte von solch absurden Situationen erleben, wie zum Beispiel meinen ersten Besuch im Kreml? [...] Manchmal sage ich mir, dass ich mein Leben wohl nur träume und dass ich sehr bald aus all dem erwache" (S. 107 f.).

In Havels eingängig geschriebenen Erinnerungen stehen die Jahre seit der Präsidentschaft im Mittelpunkt. Zum einen beantwortet er Fragen des Journalisten Karel Hvizd'ala. Ergänzt werden die Antworten durch Tagebucheinträge aus dem Jahr 2005, als das Buch entstand. Außerdem finden sich Anweisungen an seine engsten Mitarbeiter aus der Zeit seiner Präsidentschaft ab 1993, die Einblick in den Alltag des tschechischen Staatsoberhaupts gewähren.

Havel wurde in der Tschechoslowakei vorgeworfen, dass er seine erste Auslandsreise als Präsident im Januar 1990 nach Deutschland antrat. Er, der als Dramatiker um die Bedeutung von Gesten und Inszenierungen weiß, wollte damit vor allem Vorurteile abbauen. „Ich bin nicht den vorletzten Okkupanten besuchen gefahren, nicht einmal den letzten, das heißt die DDR, sondern das demokratische Westdeutschland, das sich befreiende Ostdeutschland und zwei sich vereinigende Deutschlands." (S. 132)

Längst ist Tschechien Mitglied der EU und der NATO. Vielen erscheint das inzwischen selbstverständlich, wie der Autor feststellt. Dass davon eigentlich keine Rede sein kann, weiß der, der sich die Blockkonfrontation Ende der achtziger Jahre vor Augen führt. Der Wandel ist enorm. Das Wort von der „Zeitenwende“ beschreibt den Sachverhalt treffend. Auf die Frage nach dem wichtigsten Moment in seinem politischen Leben antwortet Havel konsequent: „Jenen Moment, als ich im Sommer 1991 - als Vertreter des damals vorsitzenden Landes - zum Abschluss des letzten Gipfeltreffens des Warschauer Pakts der Welt feierlich verkündete, dass dieser Pakt sich gerade aufgelöst hat, halte ich für einen der ganz besonderen Momente meines Lebens. Es geschah darüber hinaus in Prag, einer Stadt, die der Pakt dreiundzwanzig Jahre vorher überfallen hatte." (S. 343 f.)

Havel war stets ein Befürworter der europäischen Integration. Nach der Lektüre von Dokumenten der EG und der EU sprach er 1994 aber zu Recht von einem komplizierten 
und unübersichtlichen Paket, das nur mehr Professionelle verstünden, nicht aber die Bürger. Was Havel damals seinen Vertrauten mitteilte, hat bis heute nichts von seiner Aktualität eingebüßt: „Das ruft direkt nach der Entstehung einer einfachen Charta der EU und ihrer einfachen, übersichtlichen Verfassung, die dieses ganze Paket in gewisser Weise überdachen oder überwölben (nicht ändern), einfach daraus eine verständliche Sache machen würden. Ebenfalls ist mir aufgefallen, dass im Unterschied zu anderen großen europäischen Reichen der Vergangenheit die EU kein klares und einziges Oberhaupt hat und infolgedessen als eine amorphe Missgestalt erscheint, zusammengesetzt aus vielen unterschiedlich miteinander verknüpften Institutionen und Organen. Nötig wäre klarerweise das Amt eines Präsidenten (wenn es schon kein Kaiser sein kann), der rein repräsentativ sein könnte, der aber ein deutlicher Punkt der gesamten Struktur wäre." (S. 26)

Die Instruktionen an Havels engste Mitarbeiter sind indes ambivalent zu beurteilen. Einerseits erfährt der Leser, wie es bisweilen auf der Prager Burg, dem Sitz des Präsidenten, zugegangen ist. So schrieb Havel viele seiner Reden selbst; zu delegieren war seine Sache nicht. Andererseits handelt es sich häufig um Banalitäten. Havel schien sich um alles Mögliche kümmern zu wollen: vom Besteck bei Staatsbanketten über die Außenbeleuchtung seines Amtssitzes bis zum Flugzeug für einen Staatsbesuch.

Hingegen berichtet der Autor eindrucksvoll von zahlreichen Begegnungen aus den vergangenen Jahren. Mit Václav Klaus, dem ehemaligen Ministerpräsidenten und heutigen Staatspräsidenten Tschechiens, verbindet ihn eine gegenseitige Abneigung. Insbesondere Klaus' Marktradikalismus ist Havel ein Dorn im Auge. Michael Gorbatschows historisches Verdienst schätzt er als „riesig“ ein - „ohne ihn wäre der Kommunismus zwar auch zusammengebrochen, vielleicht aber erst zehn Jahre später und auf Gott weiß welche wilde und blutige Art“ (S. 22). Zu den wenigen wirklichen Freunden aus der Politik rechnet Havel neben Bill und Hillary Clinton auch Richard von Weizsäcker, der ihm während seiner Amtszeit sehr geholfen habe.

Havel, der als Autor absurder Texte bekannt wurde, erlebte bisweilen selbst peinlich-absurde Situationen, wie folgendes Beispiel zeigt: Im Jahr 2005 verbrachte er zwei Monate in Washington, um in der Kongressbibliothek zu arbeiten. Des Englischen zwar mächtig, hatte er aber Schwierigkeiten die amerikanische Aussprache stets auf Anhieb zu verstehen, was mitunter zu Missverständnissen führte. „Gestern wollte ein jüngerer Schwarzer, mit dem ich im Aufzug fuhr und der mir sagte, wie sehr er mich schätzt, ein Autogramm von mir. Dann murmelte er etwas, das ich nicht verstand, das aber offenbar eine Frage war. Der Einfachheit halber sagte ich ,Ja'. Gleich darauf aber ging mir auf, was er gefragt hatte: ob ich ,Die unerträgliche Leichtigkeit des Seins' geschrieben habe. Jetzt noch die Antwort zu verändern ging nicht, fliehen war auch nicht möglich ... Wirklich eine Kundera-Situation." (S. 144) 